\title{
Chapter 8 \\ The Nonduality of Motion and Rest: Sengzhao on the Change of Things
}

\author{
Chien-hsing Ho
}

\section{Introduction}

Traditional Chinese culture typically affirms and highlights the changing nature of things. For non-Buddhist Chinese thinkers in general, the myriad things are both real and ever-changing, and there is no unchanging reality lying beyond or behind. They might readily agree on the Indian Buddhist teaching of impermanence. Yet in contrast to this general trend, in his essay "Things Do Not Move" (Wubuqian Lun 物不遷論; henceforth $W L),{ }^{1}$ Sengzhao 僧肇 (374?-414 CE), a prominent Chinese Buddhist philosopher of Mādhyamika leanings, appears to argue for the thesis that the myriad things do not move in time (henceforth, the nonmoving thesis). To say that things do not move in time is to say they do not change, and so Sengzhao appears to dismiss as unreal all changes of the world.

The nonmoving thesis runs counter to the tradition, as well as being counterintuitive. For some, it even goes against the Mahayana doctrine of emptiness (śünyatā, kong 空). Nevertheless, Sengzhao takes the nonmoving thesis to be a direct corollary of certain statements in Mahayana sutras and Mādhyamika treatises to the effect that things do not come and go. Moreover, he seems to think that ideas similar to the nonmoving thesis were already espoused by Confucian and Daoist sages. ${ }^{2}$

\footnotetext{
${ }^{1}$ This essay and three others were, long after Sengzhao's death, compiled to form the main core of the treatise known as the Zhao Lun 肇論. For an acceptable English translation of the essay, see Chan 1963. Sengzhao also wrote a commentary on Kumārajīva's Chinese translation of the Vimalakìrtinirdeśa Sütra, the Weimojie Suoshuo Jing 維摩詰所說經, which forms a significant portion of the Zhu Weimojiejing 注維摩詰經 traditionally attributed to him. In this paper, traditional Chinese Buddhist texts are cited according to the Taishō Shinshū Daizōkyō.

${ }^{2}$ See Zhao Lun, T 45, 1858: 151b5-6 and b21-24, for the reference to Confucius and Zhuangzi. We discuss this issue in Sect. 4.

C.-h. Ho $(\bowtie)$

Academia Sinica, Taipei, Taiwan

e-mail: hochg@sinica.edu.tw
} 
Sengzhao wrote the essay with the intent of clarifying and defending these statements. We also know that the topic of motion and rest was a much-debated issue in the Chinese philosophical circles of his time. Still, a number of questions need to be addressed in this context. Are Sengzhao's arguments for the nonmoving thesis sound, or at least prima facie persuasive? What is his true stance, in the WL, on the change or nonchange of things? What are the main problems that beset the stance or the nonmoving thesis? Herein, I attempt to address these questions, with a view to elucidating Sengzhao's thought on the relationship between change and nonchange.

It may be said at the outset that Sengzhao's discussions in the WL are not very consistent, which leads easily to misunderstandings of his overall stance on the change/nonchange of things. Instead of holding that permanence is real, and change is an illusion, Sengzhao thinks that the myriad things are both changing and unchanging. For him, the nonmoving thesis follows from the discernment that things change continuously without there being any enduring stuff against the background of which change takes place. Consequently, he contends that one must not leave change to seek for nonchange. Further, although Sengzhao's emphasis in the $W L$ is on the thesis that things do not move in time, there is no definitive denial of the view that the myriad things somehow move in time.

The remainder of this paper is organized as follows. In Sect. 2, I offer some conceptual clarifications as well as preliminary observations. In Sect. 3, I examine, attempt to reconstruct, and evaluate Sengzhao's arguments for the nonmoving thesis. In Sect. 4, I elucidate his overall stance on change/nonchange and discuss the main problems that face the stance or the thesis. Section 5 concludes.

\section{Conceptual Clarifications}

A pressing issue is why, in the $W L$, Sengzhao wants to argue for the nonmoving thesis, i.e. that the myriad things do not move in time, so they do not really change. It is evident from the text that he thinks the nonmoving thesis is implied by the statements from Mahayana sutras and Mādhyamika treatises that he cites herein. He cites a line from a Prajñāpāramitā Sūtra that states that things do not come or go and are motionless. He attributes to a Mādhyamika treatise the claim that things are changeless and have nowhere to come from or go to (Zhao Lun, T 45, 1858: 151a10 11 and b16-17). These statements suggest that the myriad things do not move in time. Then, we can reasonably assume that a main motive for Sengzhao's writing the $W L$ is to clarify and defend these statements.

In the Indian context, such statements concern mainly the ultimate illusoriness of all things. For instance, for Nāgārjuna (c. 150-250 CE), founder of the Madhyamaka school of Mahayana Buddhism, since all things are dependently originated, all things are empty (śünya) in the sense of having no inherent, independent and unchanging existence or nature (svabhāva, zixing 自性). The emptiness of things strips them of any substantial ground and allows their deeply illusory character to be 
recognized. Consequently, all changes, such as coming and going, are illusory and ultimately unreal.

However, as we shall see, Sengzhao's defense of the nonmoving thesis is based on a different rationale. In the $W L$, he does not mention such terms as "empty" (kong 空) and “void" ( $x u$ 虛); nor does he speak of things as illusory. Further, although he uses both the terms "real" (zhen 真) and "conventional" (su 俗), which suggest, respectively, ultimate truth and conventional truth in the Mādhyamika doctrine of twofold truth/reality, what is said to be real in the $W L$ differs palpably from what he says about ultimate truth in the other essays of the Zhao Lun. ${ }^{3}$ Indeed, the defense proceeds with little or no regard to the Mahayana or Mādhyamika doctrine of emptiness. We may say that the WL is the product of Sengzhao's own reflections on the change of the myriad things rather than concerning the doctrine of emptiness, even though both the reflections and the doctrine of emptiness serve to affirm, in a certain sense, the nonmoving thesis.

Before examining Sengzhao's ideas in detail, it will be prudent to elucidate, in brief, the concept of time and its cognates with which we will be dealing. For Buddhists, time (or the stream of time) consists of three periods: past, present, and future. In the $W L$, Sengzhao does not refer explicitly to the future period of time. This may well be because for him, things in the future are simply nonexistent. Rather, he speaks of the past and present and appears to take things in the two time periods to be existent.

Buddhism in general refuses to confer on time any ontologically independent, sui generis existence. Nāgārjuna, in particular, asserts that time depends upon things and in consequence does not really exist at all. ${ }^{4} \mathrm{He}$ presumably considers the concept of time as arising expediently and conventionally on the evidential basis of the flow of things. In his writings, Sengzhao does not explicitly comment on the ontological status of time, so we are unable to say anything conclusive in this regard. It is quite likely that he agrees with the general Buddhist denial of independent reality to time and views the past and present as conceived expediently on the basis of past and present things. In light of the foregoing, although our analysis refers, expediently, to the notions of time, past, present, etc., this should not be construed as our ascribing to Sengzhao any realist conception of time.

We can conceive that the myriad things flow in time in two opposite directions. On one hand, we can think of things as moving in time from the past toward the future. After all, we all seem to move from our past (when we were younger) to the

\footnotetext{
${ }^{3}$ For Sengzhao, ultimate truth is formless, ineffable, and realizable only by the quiescent mind of a Buddhist sage. None of these characteristics apply to what is said to be real in the WL. Herein, in T 45, 1858: 151a28, Sengzhao regrets that people have the real before their eyes without their knowing it. This indicates that the real in the $W L$ is available to our eyes. Thus, the Tang dynasty commentator Yuankang 元康 is not wrong when he comments that the $W L$ "clarifies [the notion of] existence to expound the teaching of conventional truth." See Zhaolun Shu 肇論疏, T 45, 1859: $166 \mathrm{c} 16$.

${ }^{4}$ Nāgārjuna writes in the last verse of the 19th chapter of his Mūlamadhyamakakārikā: "If time depends on things (bhāva), where is there time apart from things? As things do not really exist, where would time exist?" See Saigusa 1985: 548.
} 
present, to what we are now. The myriad things, then, flow in time in the futurebound direction (henceforth FD). On the other hand, given that present things will be in the past almost immediately, we can also think of them as moving from the present to the past, i.e. in the past-bound direction (PD). Of the two directions, modern conventional wisdom prefers FD to PD. However, not only does PD make sense, it is close to the claim of the Buddhist Sarvāstivāda school that things move from the future to the present and then from the present to the past. ${ }^{5}$ Sengzhao is familiar with the claim, so he writes in the Zhu Weimojiejing: "If things abided permanently, [they would move] from the future to the present, and from the present to the past. If things thus pass through the three time periods, they would have coming and going. Since things do not abide permanently, they have no coming and going." This passage suggests that if Sengzhao is to take the myriad things to move in time, he may favor the PD view over FD. He is aware of the two ways of conceiving the flow of things, so when we consider his arguments for the nonmoving thesis in the next section, we need to take into account both FD and PD.

Meanwhile, we can divide the stream of time conceptually into an infinite number of temporal moments. Correspondingly, we can think of a thing that moves in time as consisting of an indefinite number of moment-things. In this context, let us distinguish a moment-thing from a continuum-thing. ${ }^{7}$ A moment-thing is a thing that exists only in, or relative to, one temporal moment, which is, so to speak, its present or immediate moment. By contrast, a continuum-thing is an ever-changing thing that proceeds in time for two or more temporal moments. It normally consists of an indefinite number of preceding and succeeding moment-things. Since these moment-things are of one and the same causal continuum (qua continuum-thing), we can conventionally take them to be the same thing, similar to the way we take baby Obama, Senator Obama, and President Obama to be the same person.

As is well known, some Buddhist schools endorse a theory of momentariness to the effect that a thing arises and perishes in one and only one temporal moment. However, Indian Mādhyamikas generally do not accept this theory, and Sengzhao concurs with them in holding that, from the perspective of ultimate truth (zhendi 真 諦), things do not really arise at all. Yet whereas Sengzhao does not in the WL refer to the notion of moment, he does so elsewhere where he seems to think that the myriad things are momentary. ${ }^{8}$ Arguably, a proper understanding of his stance on

\footnotetext{
${ }^{5}$ For this claim, see Apidamo Jushe Lun 阿毘達磨俱舍論, T 29, 1558: 104b28-c29.

${ }^{6}$ Zhu Weimojiejing, T 38, 1775: 347a14-17. It is here, but not in the WL, that Sengzhao speaks of the future. We shall come back to this passage in Sect. 4.

${ }^{7}$ The two terms, "moment-thing" and "continuum-thing," are coined by me, and are not present in the $W L$. However, Buddhist thinkers generally view a person as a psychophysical continuum, and some of them take all things to be momentary. It will be seen that this terminological distinction works quite well for our analytical exposition of Sengzhao's stance.

${ }^{8}$ A line in the Weimojie Suoshuo Jing (T 14, 475: 541b25-26) reads "just like a magical illusion or a lightning flash, things do not wait for each other and do not even abide for one moment (nian 念)." Sengzhao comments thereon: “Things are ever changing and new, like a lightning flash; they arise and perish without waiting [for things of the succeeding moment]. Sixty moments pass away in one finger snap. When things do not even abide for one moment, how can one expect them to
} 
the changing of things requires that we take him to recognize the momentariness of things, without ascribing to him a full-fledged theory of momentariness. In our view, a moment-thing is what is said to be real in the $W L$; namely, herein the word "real" refers to moment-things (or some state of affairs involving them). Nonetheless, the notion of moment-thing is rather intricate, and we cannot dwell on it in this paper. For our purposes, suffice it to say that since Sengzhao implies that the real is available to our eyes, we should understand a moment-thing as an object of perceptual experience rather than as an abstraction like a mathematical point.

Since a continuum-thing proceeds in time from moment to moment, we can reasonably hold that a continuum-thing is, while a moment-thing is not, moving in time. This provides a way to understand Sengzhao's nonmoving thesis. In addition, a given thing, X, at a certain moment of time can be viewed either as a moment-thing or as (part of) a continuum-thing. Thus, in a sense, $\mathrm{X}$ is both moving and not moving.

\section{Sengzhao's Arguments}

As I see it, there are, in the $W L$, two explicit arguments for the nonmoving thesis: I call them the main argument and the causality argument. In addition, a passage in the text can be read as involving two supportive arguments for the main argument.

The main argument (A) can be formulated as follows ${ }^{9}$ :

A1: Past things are present in the past and do not exist in the present.

A2: Past things do not come to the present.

A3: Likewise, present things do not go to the past.

A4: Therefore, things do not move in time.

As said before, we can think of things both as moving from the past toward the future (FD) and as from the present to the past (PD). Consequently, when we consider the flow of things in time, we need to take into account both FD and PD. In this argument, if premises A2 and A3 hold, we would have to accept the truth of the conclusion A4, and so of the nonmoving thesis. However, even if we take premise A1 to be true, it remains questionable whether we can derive A2 from it.

abide any longer? As things do not abide, they are like a magical illusion. Being like a magical illusion, they are not real. Not being real, they are empty" (Zhu Weimojiejing, T 38, 1775: 356b1215). Herein, the temporal nonabidingness of things indirectly implies their emptiness; it is in this manner that Sengzhao's thought in the WL may be connected to the doctrine of emptiness. Still, we need to bear in mind that Sengzhao's point in the WL is that things (qua moment-things) do not last for more than one moment, but not that things do not even abide for one moment.

${ }^{9}$ Zhao Lun, T 45, 1858: 151b1-6. Immediately before this, Sengzhao writes in T 45, 1858: 151a28-b1: "People already know that past things do not come [to the present. Yet, they] hold that present things can go [to the past]. If past things do not come [to the present], where can present things go?" Elsewhere he notes that "because things do not come [from the past to the present], they do not go from the present to the past" (T 45, 1858: 151c7). It is clear that premise A3 is based analogically on premise $\mathrm{A} 2$. 
Both A2 and A3 seem counterintuitive and problematic, so they require supporting arguments.

Here is the supporting argument (B) for premise A2 (Zhao Lun, T 45, 1858: 151c14-15):

B1: If past things come to the present, they exist in the present.

B2: Past things do not exist in the present.

B3: Therefore, past things do not come to the present.

At first sight, this modus tollens argument looks sound, presumably because we take it to show that past things do not come to the present as they were on the ground that past things do not exist in the present as they were. Yet, this is not sufficient to support A2 and the nonmoving thesis. On our general understanding of the thesis, in order to show the thesis to be true, A2 should mean that past things do not come to the present in any way, that is, neither as they were nor in a changed form. Then, to support $\mathrm{A} 2$ and the nonmoving thesis, one needs to show this revised $\operatorname{argument}\left(\mathrm{B}^{*}\right)$ to be sound too:

B1*: If past things (changing themselves) come to the present, they exist in the present in a changed form.

B2*: Past things do not exist in the present in a changed form.

B3*: Therefore, past things do not (changing themselves) come to the present.

Common sense tells us, and many of us would agree, that B2* is false. Yesterday's Barack Obama must somewhat differ, physically and psychologically, from today's Barack Obama. Even so, it makes perfect sense to say that yesterday's Obama exists today in a new and changed form. Given the implausibility of B2*, both B3* and A2 remain problematic.

The inference from A2 to A3 is based on analogical reasoning: as things do not come from the past to the present, they, analogically, do not go from the present to the past. Plainly, such reasoning is far from persuasive. However, we detect in the text this supporting argument (C) for A3 (Zhao Lun, T 45, 1858: 151c14-16):

C1: If present things go to the past, they exist in the past.

C2: Present things do not exist in the past.

C3: Therefore, present things do not go to the past.

Again, this modus tollens argument looks sound. What exist in the past are past things, not precisely present things. Given the change of things moving in time, there must be differences between present and past things or between a thing in the present and the same thing in the past. Yet once again, this is not sufficient to support A3 and the nonmoving thesis. On our general understanding of the thesis, in order to show the thesis to be true, A3 should mean that present things do not go to the past in any way. Then, one needs to show this revised argument $\left(\mathrm{C}^{*}\right)$ to be sound too:

$\mathrm{C} 1 *$ : If present things (changing themselves) go to the past, they exist in the past in a changed form.

$\mathrm{C} 2 *$ : Present things do not exist in the past in a changed form.

C3*: Therefore, present things do not (changing themselves) go to the past. 
$\mathrm{C} 2 *$ is implausible. The present Obama would be in the past a minute later, at which time the Obama who was in the present a minute ago is then in the past. We can say that the (just) present Obama is now in the past in a changed form in the sense that he now belongs to the past, not the present. ${ }^{10}$ In addition, it is experientially evident that no present things can always stay in the present, which would here mean they go to the past and stay there in a changed form. Given the implausibility of $\mathrm{C} 2 *$, both $\mathrm{C} 3 *$ and $\mathrm{A} 3$ remain problematic.

Since A2 and A 3 are both problematic, the main argument fails to be convincing. Let us now look at the causality argument (D) (Zhao Lun, T 45, 1858: 151c23-25):

D1: A present effect and its cause do not exist at the same time. ${ }^{11}$

D2: The effect arises by dint of the cause.

D3: The cause does not cease in the past.

D4: The cause does not come to the present.

D5: Therefore, the cause does not move in time.

Here, Sengzhao appears to consider only the flow of things from the past to the present; this is why he says that the past cause does not come to the present. D1 and D2 seem acceptable. D3 is derivable from D2 in that the cause must exist (in a certain moment or period) in the past to have the power to give rise to the effect in the present. D4 is derivable from D1. Then, given that D5 hinges on the truth of D3 and D4, if we accept D1 and D2, we may have to concede that, for any present effect, its cause exists in the past and does not move in time to the present.

Suppose a past seed functions as the cause to give rise to a present sprout as the effect. The sprout arises by dint of the seed (and certain causal factors), and the two do not exist simultaneously. However, the seed and the sprout can be viewed as two different stages of the same plant. The plant exists in the past as seed, yet it also exists in the present as sprout. The seed and the sprout do not exist simultaneously as two distinct things. Still, the plant qua cause somehow comes to the present and exists then in a new and changed form as effect. Then, D4 is not tenable, because the cause does come to the present, though in a changed form. Moreover, to really support the nonmoving thesis, the argument $\mathrm{D}$ should allow that we take a given seed at a certain moment, say, $\mathrm{T}_{1}$, to be the past cause and the same seed of the immediately succeeding moment, $\mathrm{T}_{2}$, to be the present effect. Clearly, we can say that the seed at $T_{1}$ comes to the present as the seed at $T_{2}$; namely, the past cause comes to the present. Thus, D4 is untenable. In consequence, the causality argument fails to be convincing too.

\footnotetext{
${ }^{10}$ Even if the two time periods, past and present, as conceptual constructs, are not real, it remains true from our experiential perspective that the two Obamas differ from one another while conventionally being the same person. Meanwhile, if one insists that the two Obamas are precisely identical, then, given the implausibility of $\mathrm{C} 2$, it would appear that present things do go to the past, which falsifies the nonmoving thesis.

${ }^{11}$ In Zhu Weimojiejing, T 38, 1775: 346b28, Sengzhao distinguishes a cause (yin 因) from a causal factor (yuan 緣) by noting that a cause gives birth to an effect that follows it, while a causal factor provides assistance to an effect that exists simultaneously with it. Thus, as stated in D1, an effect and its cause do not exist simultaneously.
} 


\section{Sengzhao's Stance on Change/Nonchange}

We have shown that Sengzhao's main argument and the causality argument are unsound or unpersuasive. However, we should not be too quick to conclude that the failure of these arguments means that the nonmoving thesis is false. Remarkably, it is very likely that Sengzhao does not take the arguments to be conclusive. Whether or not he takes them to be conclusive would depend on his overall stance on the change (and nonchange) of things. In this section, I elucidate Sengzhao's stance and discuss problems that it faces.

As noted at the beginning of the paper, Sengzhao holds that the myriad things are both changing and unchanging. That this is so is clear from the following passage from the WL (Zhao Lun, T 45, 1858: 151a11-14):

\section{Concerning the intent of [the scriptural saying that things are] not moving, does it mean [that one should] discard motion in order to seek rest? [No.] One must seek rest within mov- ing things. As one must seek rest within moving things, things are at rest while being in motion. As one must not discard motion in order to seek rest, things are moving while being at rest. Thus, motion and rest are from the beginning not different, yet the deluded think they are distinct.}

Given that one seeks rest within moving things, what is at rest should at the same time be in motion. For Sengzhao, motion and rest are nondual in that they are two intertwined aspects of one and the same actuality, which can be characterized as changing or unchanging, depending on the perspective one takes. This view is in perfect accord with the paradoxical character of Sengzhao's conception of the myriad things as revealed throughout the Zhao Lun. For him, the myriad things are paradoxically both one and many, real and nonreal, formless and endowed with forms. ${ }^{12}$ In a sense, it is only natural that Sengzhao would view things as both moving and not moving.

Notably, no logical contradiction is involved here. Sengzhao is not treating an item as both $\mathrm{X}$ and not-X precisely in the same manner and the same sense at the same time. The myriad things are much like the famous duck-rabbit figure. The figure is not self-contradictory, yet we can say that it is both duck and rabbit, and neither duck nor rabbit. It looks like a duck or a rabbit, depending on the perspective we take. It is neither duck nor rabbit insofar as it is not exclusively a duck or a rabbit. To further clarify this issue, we may say a few words on Sengzhao's understanding of language as provisional. ${ }^{13}$

In our ordinary understanding and use of nominal words, we may tend to entify their referents, taking the latter to be self-identifying and distinctly demarcated entities. We may further take the words to connote the determinacy of their referents such that the latter are seen as possessing determinate properties. We believe that

\footnotetext{
${ }^{12}$ For Sengzhao's paradoxical conception of the myriad things, see Ho 2013.

${ }^{13}$ For more discussions on the topic, see Ho 2013. Connected with this provisional understanding of language is Sengzhao's thesis of ontic indeterminacy to the effect that given anything X, no linguistic term can truly and conclusively be applied to $X$ in the sense of positing a determinate form or nature therein. See also Ho 2014 for discussions of Sengzhao's ontological stance.
} 
something that can reasonably be expressed by the word "existent" is definitively existent, while that expressed by "nonexistent" is definitively nonexistent. We may further suppose that existence and nonexistence are mutually exclusive and jointly exhaustive, and that a given thing must be either existent or nonexistent, but not both or neither.

Sengzhao dismisses this ordinary understanding of the way nominal words function. In his view, we should understand and use words provisionally such that they are not taken to connote any determinacy of their referents. In the provisional use of words, nominal words apply to their referents without ascribing to them any determinate and exclusive properties. The provisional use of the word $X$ for a thing does not mean that the thing is definitively $X$ or has a determinate $X$-property. The thing can be non-X too, and as such can be expressed provisionally by the word non-X. For instance, applying the word "existent" to a thing does not mean that the thing is definitively and exclusively existent. It is only, let us say, provisionally existent, which does not exclude its being expressed by the word "nonexistent." These words do not denote anything definitively and exclusively existent or nonexistent. Likewise, we can provisionally, and without contradiction, apply "moving" and "not-moving" to the myriad things. Contradictions only arise when we take them to denote determinate and mutually exclusive entities, which Sengzhao would not.

In this vein, we can understand this passage in the WL (Zhao Lun, T 45, 1858: 151b13-18):

Thus, [when the Buddhist sage] said that things go, he did not mean that they definitively go; [his intent is] to prevent people from adhering to the idea that things are permanent. When he said that things stay, he did not mean that they definitively stay; [his intent is] to dispense with what people call the passing of things. How can "going" mean definitively passing, and "staying" definitively abiding? ... The two expressions ["going" and "staying"] refer to one and the same thing. ${ }^{14}$ How can it be the case that as they differ in letters, they must refer to different things?

Given common people's non-provisional understanding of words, what they call the passing of things is definitively passing, and nothing can be both definitively passing and definitively staying at the same time. On Sengzhao's view, we must not construe the Mahayana texts that way. In the provisional use of words, we can apply the terms "passing" and "staying" to the same things at the same time without contradiction. Overall, things are, provisionally, both moving and not moving, but, definitively, neither moving nor not moving.

Still, one would ask on what specific grounds things can be said to be both moving and not moving. Here let us consider the notions, introduced above, of "momentthing" and "continuum-thing." A given thing, X, at a certain moment of time can be viewed either as a moment-thing or as part of a continuum-thing. If we view $\mathrm{X}$ as a moment-thing, then, existing only relative to its immediate moment, $\mathrm{X}$ is not moving in the sense of passing through different moments of time. In contrast, if we view $\mathrm{X}$ as part of a continuum-thing, then we can say it is moving on the ground that

\footnotetext{
${ }^{14}$ It is said in T 45, 1858: 151c11-12 that "although going and staying are distinct [concepts], they refer to the same thing."
} 
the continuum, of which it is a part or phase, proceeds in time from moment to moment. Consequently, $\mathrm{X}$ is both moving and not moving.

For Sengzhao, it seems, a thing originates by depending on a cause and various causal factors, and all moment-things are immediately preceded by their causes. He most likely recognizes the causal relationship between the preceding and succeeding moment-things of a continuum-thing. Given the ever-changing nature of things, a preceding moment-thing as the cause differs significantly from its succeeding moment-thing as the effect. Still, we can say that the preceding moment-thing gives rise to, or changes itself to become, the succeeding moment-thing. The two momentthings can, indeed, be conventionally taken to belong to one and the same continuumthing. Such a continuum-thing appears to be conceived on the basis of preceding and succeeding moment-things. It would seem, then, the continuum-thing is less real than its constituent moment-things because it is more conceptually and conventionally conceived in dependence on our conceptual scheme than the moment-things are. ${ }^{15}$ This explains why Sengzhao contends that the Buddha's talk about things not being moving is talk concerning the real, whereas his talk about things being moving is talk concerning the conventional. ${ }^{16}$ Precisely in this sense, we can say, for Sengzhao, the unchanging aspect of the myriad things is ontologically higher than their changing aspect.

Now, if Sengzhao thinks that the myriad things are both moving and not moving, he would not mean to take the arguments that we discussed above to be conclusive, definitively showing the exclusive truth of the nonmoving thesis, and the problems that we identified with his arguments would not seriously count against the value of the WL. This being so, we should instead see the arguments as heuristic, intended to induce one to recognize an important point about the myriad things, the point that is expressed by the nonmoving thesis.

There is another way of reading Sengzhao's arguments in the WL. As cited above, Sengzhao elsewhere avers that since things do not abide permanently, they do not move in time and thereby have no coming and going. If so, to hold that things move in time is to endorse the view that things pass through different time periods with an enduring stuff. By contrast, the nonmoving thesis amounts to merely saying that things do not move in time with an enduring stuff. However, this reading does not tally well with our text, so it can hardly make Sengzhao's arguments any more persuasive. Nonetheless, it is very likely that the view that things abide constantly

\footnotetext{
${ }^{15}$ In Sengzhao's ontology, it seems to me, the more an item is conceptually presented or presentable, the less it is real. For a related exposition, refer to Ho 2014.

${ }^{16}$ Zhao Lun, T 45, 1858: 151c2-3. As noted before, the terms "real" and "conventional" here do not stand for ultimate truth and conventional truth of the standard Mādhyamika doctrine of twofold truth. It is not uncommon for a Mādhyamika philosopher to propose a multileveled theory of twofold truth. For instance, Jizang 吉藏 (549-623 CE), the leading Chinese Mādhyamika after Sengzhao, set forth the doctrines of "three levels of two truths (sanchong erdi 三重二諦)" and "four levels of two truths (sichong erdi 四重二諦)." Therefore, we can understand moment-thing and continuum-thing to belong to, respectively, the ontologically higher (hence real) and lower (hence conventional) levels of Sengzhao's conventional truth, which is, for him, basically the myriad things. For the further discussion of Jizang's these doctrines, see chapter 8 of this anthology.
} 
without change remains a main target of criticism in the $W L$. We now consider this issue in some detail.

To say that things move in time is ambiguous, in that it can mean either that things move in time with an enduring stuff or that things move in time with no enduring stuff. This, coupled with the nonmoving thesis, gives us three different views of things in time:

View 1: Things move in time with an enduring stuff.

View 2: Things move in time without any enduring stuff.

View 3: Things, being momentary, do not move in time.

According to view 1, while things move and change in time, there is an enduring core that remains the same through all changes. This view was generally held by Hindu thinkers in India but was dismissed by Indian Mādhyamikas. Common people are inclined to accept the view. Thus, Sengzhao writes in the WL: "people think that a person possesses the same substance in youth and in maturity, that the same stuff persists over a hundred years" (Zhao Lun, T 45, 1858: 151b24-25). Sengzhao would repudiate this view without hesitation.

I take view 2 to mean that though things move in time, they are ever-changing in their entirety, such that nothing in them endures for more than one moment. Such a moving thing is what we have referred to as a continuum-thing. View 3 says what the nonmoving thesis states, and it is true of all moment-things. Significantly, view 2 and view 3 together constitute the stance we have attributed to Sengzhao, namely, that the myriad things are moving and not moving in time.

We can further appreciate the intimate relationship between view 2 and view 3 by considering an hermeneutical puzzle in the WL. In that text, Sengzhao mentions both Confucius and Zhuangzi. He writes as if the two non-Buddhist sage thinkers, at least implicitly, endorsed view 3, whereas the directly relevant lines and ideas attributed to them in the $W L$ at best affirm only view $2 .{ }^{17}$

I think that this problem of interpretation can be resolved insofar as we recognize that, for Sengzhao, view 3 arises naturally from view 2. If one discerns that a thing changes moment by moment over a period of time without there being any enduring stuff in the process, one may conclude that the thing at a given moment of the process exists only relative to the moment and does not exist in any preceding or succeeding moments. Such a moment-thing has no coming or going, and this accords well with view 3. Given that Sengzhao takes Confucius and Zhuangzi to embrace view 2 , it is natural for him to think that they implicitly endorsed view 3 .

Views 2 and 3 concern the same phenomenon, but approach it from different perspectives: respectively, the perspective of a continuum and that of a moment.

\footnotetext{
${ }^{17}$ Zhao Lun, T 45, 1858: 151b5-6 and b21-24. Tan refers to a parable in the Zhuangzi that involves Confucius and his disciple Yan Hui 顏回 and observes that while the Zhuangzi uses the parable to illustrate the ongoing change of things, "Sengzhao uses it to justify his argument that past things stay in the past, and present things stay in the present" (Tan 2008, 200). He claims that Sengzhao criticizes the Zhuangzi's understanding of motion. However, it is most likely that Sengzhao exploits the understanding to reinforce his nonmoving thesis.
} 
Indeed, we can say the two views are mutually dependent. On the one hand, if things move in time with an enduring stuff, namely, if view 2 is false, there would be no moment-things and view 3 would not hold. On the other hand, if there are no moment-things, which do not move in time, things would always move in time with an enduring stuff. The two views require, imply and complement each other, which, for Sengzhao, indicates the nonduality of motion and rest. Overall, in the $W L$, Sengzhao dismisses view 1, accepts view 2, and highlights view 3 .

Meanwhile, there are two main problems that beset Sengzhao's stance in the $W L$, especially the nonmoving thesis.

The first problem is that since moment-things do not move in time, any present moment-thing should remain at rest in the present. Hence, Sengzhao contends that present things stay in the present. Yet this clearly goes against our everyday experience. As we know well, no present thing or moment-thing can persist in the present. If a given present moment-thing does not persist in the present, it is reasonable to think that it has, in the moment following its appearance to us, gone into the past. Thus, a moment-thing moves in time and the nonmoving thesis is false. This seems to me to be the toughest problem for Sengzhao. However, a response can be formulated on Sengzhao's behalf.

Above, we spoke of a moment-thing existing only in, or relative to, its present or immediate moment. From our own perspective, a present moment-thing is observed to pass into the past. However, we can conceive a notion of time such that, from the moment-thing's own perspective, it always stays in its own present or immediate moment. Then, when contending that present things stay in the present, Sengzhao means to state that present moment-things always stay in their own present moments, but not in our present time; just as phenomenologically, we can never escape our own present. By contrast, in contending that past things stay in the past, he stresses that past moment-things, which exist in their own present moments, always stay in what is, from our constant present perspective, our past. This implies that we can have two different perspectives of the notion of time: our perspective and that of other things. To some, this way of resolving the problem may not be quite satisfactory. However, it should be noted that Sengzhao's fundamental contention is that (moment-)things do not move in time, and this is indeed the case for both present and past moment-things in respect of their immediate moments of time.

The second problem is that the $W L$ was traditionally criticized by some Buddhists for taking things to be permanent, for the reason that things are held to always stay in a period of time, past or present..$^{18}$ If things are permanent, they would be endowed with an inherent existence or nature and would thereby be nonempty. Consequently, Sengzhao's stance runs counter to the central teaching of Madhyamaka. Against this criticism, we remark that, on Sengzhao's view, a moment-thing is unchanging in relation to its own immediate moment, but not to the three time periods. In addition, his nonmoving thesis hinges on the idea that a continuum-thing changes in time moment-by-moment without any enduring stuff. Thus, neither a moment-thing nor a continuum-thing abides through time without changing.

${ }^{18}$ For a recent study on this and related issues, see Liu 2010. 
The view that a moment-thing stays in its own moment might suggest that a moment-thing has the inherent nature of thus staying and thereby fails to be empty. However, for Sengzhao, to say that a thing stays in a period of time does not mean it definitively stays in that period. The intention of speaking in such terms is to steer people away from the idea that things definitively move in time. Given Sengzhao's provisional understanding of language, we should not take him to posit any inherent or determinate nature in moment-things.

This second problem arises partially because, in the $W L$, Sengzhao adopts a more or less conventional position concerning the ontological status of the myriad things: he does not speak of them as illusory or empty. This leads him to claim that past and present things exist in their own time periods. Above, we took this to mean that moment-things exist only relative to their own moments. Yet Sengzhao can go one step further and, as he does in the Zhu Weimojiejing, maintain that the myriad things do not even abide for one moment. This nonabidingness would strip the myriad things of any substantial ground and reveal them to be illusory and empty. However, Sengzhao does not take this additional step explicitly in the $W L$, with the result that one may mistakenly take him to posit inherent nature in the myriad things.

Sengzhao does not present the notion of emptiness in the $W L$, even though it plays a major role elsewhere in his thought. This is probably because in the WL he is concerned to stress the nonduality of motion and rest. His intent may also be to highlight the importance of every living present. Sengzhao notes that the completion of a mountain lies in the first basket of soil, but the fact is that for the completion every basket is important. The text implies that whatever we do in our day-to-day life, virtuous or vicious, the deed would always exist relative to its immediate moment (Zhao Lun, T 45, 1858: 151c19-23). The view then arises immediately that we need to value every moment of our life as we live it, and live and act the best way we can. This is difficult to achieve, and may be rendered even more difficult if we are too quick to think of the myriad things, our life included, as illusory.

\section{Conclusion}

I have investigated the WL to examine Sengzhao's arguments for the thesis that things do not move in time. I have also elucidated his stance on the change/nonchange of things and discussed related problems. Although Sengzhao apparently attempts to show the plausibility of the thesis, he makes it clear that one must not leave change to seek for nonchange. Indeed, the thesis follows from the discernment that things change from moment to moment without there being any enduring stuff in the process.

Philosophers such as Parmenides, Plato and Śankara were inclined to think that change is an illusion of the senses, and that only permanence is real. Indian Mādhyamikas would speak of change as ultimately illusory, yet while rejecting permanence as well. However, Sengzhao, in the $W L$, takes our eyes to have direct access to the real and views the myriad things as both changing and unchanging, 
resulting in the affirmation of the nonduality of motion and rest. Among philosophical works that confer a higher ontological status on nonchange over change, Sengzhao's essay, the $W L$, is unique and well worth pondering.

\section{References}

Apidamo Jushe Lun 阿昆達磨俱舍論 (The Abhidharmakośabhāsya, Commentary on the Treasury of Abhidharma). By Vasubandhu. Trans. by Xuanzang 玄牀. T 29, 1558.

Chan, Wing-tsit, ed. and trans. 1963. A Source Book in Chinese Philosophy. Princeton, NJ: Princeton University Press.

Ho, Chien-hsing. 2013. "Ontic Indeterminacy and Paradoxical Language: An Analysis of Sengzhao's Linguistic Thought." Dao: A Journal of Comparative Philosophy 12.4: 505-522.

Ho, Chien-hsing. 2014. "Emptiness as Subject-Object Unity: Sengzhao on the Way Things Truly Are." In Jeeloo Liu and Douglas Berger, eds., Nothingness in Asian Philosophy. New York: Routledge, 104-118.

LiU Le-heng 劉樂恆. 2010. “Wu Buqian Zhengliang Lun Bianxi 物不遷正量論辨析 (A Critical Analysis of the Wu Buqian Zhengliang Lun).” Hanxue Yanjiu 漢學研究 (Chinese Studies) 28.1: 191-223.

Saigusa, Mitsuyoshi. 1985. Nāgārjuna's Mūlamadhyamakakārikā-s: Texts and Translations. Tokyo: Daisanbunmei-sha.

Tan, Mingran. 2008. "Emptiness, Being and Non-being: Sengzhao's Reinterpretation of the Laozi and Zhuangzi in a Buddhist Context." Dao: A Journal of Comparative Philosophy 7.2: 195-209.

Weimojie Suoshuo Jing 維摩詰所說經 (The Vimalakītinirdeśa Sūtra). Trans. by Kumārajīva 鳩 摩羅什. T 14, 475.

Zhao Lun 肇論 (The Treatise of Sengzhao). By Sengzhao. T. 45, 1858.

Zhaolun Shu 肇論疏 (A Commentary on the Treatise of Sengzhao). By Yuankang. T 45, 1859.

Zhu Weimojiejing 注維摩詰經 (A Commentary on the Vimalakìrtinirdeśa Sūtra). By Sengzhao. T 38, 1775.

Chien-hsing Ho is Associate Research Fellow at the Institute of Chinese Literature and Philosophy, Academia Sinica, Taiwan. He received his doctorate in philosophy from the University of Delhi, India, in 1999. Afterwards, he taught for many years in the Graduate Institute of Religious Studies at Nanhua University, Taiwan, before joining Academia Sinica in 2017. He specializes in Indian and Chinese Madhyamaka, Buddhist epistemology, and Buddhist philosophy of language, with additional research interests in Chan Buddhism, Indian philosophy, and comparative philosophy. He has published articles in such international refereed journals as Philosophy East and West, Dao: A Journal of Comparative Philosophy, Asian Philosophy, the Journal of Chinese Philosophy, and the Journal of Indian Philosophy. He has also contributed book chapters to edited volumes such as Comparative Philosophy Without Borders (Bloomsbury Academic, 2015), Nothingness in Asian Philosophy (Routledge, 2014), and A Distant Mirror: Articulating Indic Ideas in Sixth and Seventh Century Chinese Buddhism (Hamburg University Press, 2014). He is currently planning a book in English on Chinese Madhyamaka. 